\title{
MAGNESIUM ADDED TO ROPIVACAINE HASTENS THE ONSET AND PROLONGS THE DURATION OF ANALGESIA AFTER SUPRACLAVICULAR APPROACH OF BRACHIAL PLEXUS BLOCK
}

\author{
Gautam Piplai ${ }^{1}$, Amrita Roy²
}

${ }_{1}^{1}$ Associate Professor, Department of Anaesthesiology, CNMCH, Kolkata.

${ }^{2}$ Final Year Postgraduate Student, Department of Anaesthesiology, CNMCH, Kolkata.

\begin{abstract}
BACKGROUND
ABSTRACT

With the introduction of newer and safer local anaesthetics and better advancement in technique for regional anaesthesia, brachial plexus block has taken over. Ropivacaine is a new amino amide local anaesthetic with less cardiotoxicity when compared to Bupivacaine. Further, magnesium sulphate is emerging to be the new adjuvant with encouraging results. Thereby we compare the effect of Magnesium Sulfate on motor and sensory block when used as an adjuvant with Ropivacaine in relation to Ropivacaine used alone.

The aim of our study is to compare ropivacaine $0.75 \%+$ normal saline with ropivacaine $0.75 \%+$ normal saline + Inj. $\mathrm{MgSO}_{4}$ in upper limb surgeries under supraclavicular block
\end{abstract}

\section{MATERIALS AND METHODS}

80 patients undergoing upper limb surgeries were randomly divided into one of the two groups containing 40 patients each. Group A received Supraclavicular Block with $15 \mathrm{ml}$ Inj. Ropivacaine (0.75\%)+ $25 \mathrm{ml}$ of Normal Saline (40 ml). Group B received Supraclavicular Block with $15 \mathrm{ml}$ Inj. Ropivacaine $(0.75 \%)+23 \mathrm{ml}$ of Normal Saline + Inj. Magnesium sulfate [2 ml (1 gm)] (40 ml). Settings and Design- Randomized single blind controlled clinical trial.

\section{RESULTS}

A faster onset, greater duration of analgesia and better quality of motor and sensory block was noted in Group B in comparison to Group A.

\section{CONCLUSION}

Ropivacaine $(0.75 \%)$ with Inj. Magnesium Sulfate is far more superior to only Ropivacaine $(0.75 \%)$ in respect motor and sensory block in Supraclavicular Block for upper limb surgeries.

\section{KEYWORDS}

Supraclavicular Block, Upper Limb Surgeries, Ropivacaine, MGSO4, Motor Block, Sensory Block, Post-Operative Analgesia.

HOW TO CITE THIS ARTICLE: Piplai G, Roy A. Magnesium added to ropivacaine hastens the onset and prolongs the duration of analgesia after supraclavicular approach of brachial plexus block. J. Evolution Med. Dent. Sci. 2018;7(09):1087-1090, D0I: $10.14260 /$ jemds/2018/247

\section{BACKGROUND}

Brachial plexus block provides a useful alternative to general anaesthesia for upper limb surgery. They achieve ideal operating conditions by producing complete muscular relaxation maintaining stable intraoperative haemodynamics and the associated sympathetic block.

Regional Anaesthesia has more to offer in orthopaedic surgery than in any other surgical specialty, either alone or as part of an anaesthetic sequence. With Regional Anaesthesia there is ${ }^{1}$ better preservation of mental functions in elderly; intact pharyngeal and laryngeal reflexes, thus decreasing the risk of aspiration; it ensures a decreased stress response in compromised patients and avoidance of difficult intubation, ${ }^{2}$ it also decreases post-operative complications associated with intubation; and it provides better postoperative pain relief without undue sedation facilitating early mobilization and discharge.

'Financial or Other Competing Interest': None.

Submission 16-01-2018, Peer Review 11-02-2018,

Acceptance 17-02-2018, Published 26-02-2018.

Corresponding Author:

Dr. Gautam Piplai,

37/1, Prince Baktiar Shah Road,

Kolkata-700033.

E-mail: gautampiplai56@gmail.com

DOI: $10.14260 /$ jemds $/ 2018 / 247$

Many approaches to Brachial Plexus Block has been described, but the supraclavicular approach is the easiest and the appropriate method for anaesthesia and management of perioperative pain in surgery below the shoulder joint. ${ }^{3}$ Supraclavicular Block is attractive due to its effectiveness, cost, performance and margin of safety. It is carried out at the level of nerve trunks where it is more compact, resulting in homogenous spread of drug throughout the plexus with fast onset and complete block.

Many local anaesthetics have been used to produce brachial plexus block. Most common among them being Bupivacaine, because of its higher potency and prolonged duration of action. One of the disadvantages is its cardiotoxicity, especially with inadvertent injection into subclavian artery. So Ropivacaine, long-acting amide, local anaesthetic with a potentially improved safety profile when contrasted to bupivacaine was developed with properties similar to bupivacaine, but having lower lipid solubility and less cardiotoxicity. 4

Different additives have been used to prolong regional blockade and shorten onset times of block. Vasoconstrictors are used to constrict the vessels, thereby reducing the vascular absorption of local anaesthetic. Additives such as opioid, clonidine, verapamil etc. Were added to local anaesthetic, but the results were either inconclusive or associated with side effects. 5 Any adjuvant with brachial 
plexus block should prolong the analgesic effect without systemic side effects, prolong the motor block and reduce the dose of local anaesthetic. Magnesium is known to produce anti-nociception, to enhance the effect of local anaesthetic when given epidurally or intrathecally, by its action on the NMDA receptors found in the peripheral nerve and Brachial plexus. 6,7

In our study, thus, we have done a comparative study between Ropivacaine $(0.75 \%)$ alone with Ropivacaine $(0.75 \%)$ in combination with Magnesium Sulfate on the onset, duration and quality of motor and sensory block in patients undergoing upper limb surgeries after supraclavicular block.

\section{MATERIALS AND METHODS}

The study protocol was approved by the ethical committee of Calcutta National Medical College, Kolkata and informed consent was obtained from every patient. In this randomized single blind controlled clinical trial eighty ASA I -II patients of either sex, aged 18-60 years, undergoing upper limb surgeries were randomly allocated, using computer generated sequence numbers, to one of the two groups, containing forty patients each.

Sample size was estimated using the first rescue analgesic requirement among the two groups as the primary variable. After conducting a pilot study on 15 patients, the average duration of analgesia was found to be $400 \mathrm{~min}$. Furthermore, detecting a difference of $10 \%$ (i.e. $40 \mathrm{~min}$ ), at $\mathrm{P}$ value $<0.05$, with a probability of detecting a difference this large, if it exits of $80 \%(1$-beta $=0.80)$, were considered. On the basis of previous study assuming within group standard deviation of $68 \mathrm{~min}$, we needed to study at least 46 patients per group to be able to reject null hypothesis that the population means of the groups are equal with probability (power) of 0.80 . So, we have taken 40 patients per group for this prospective study.

Patients having history of cardiovascular, cerebrovascular, and respiratory diseases, coagulation abnormality, uncontrolled hypertension or diabetes mellitus, severe anaemia, neuropathy, drug allergy, skin infection at site of injection were excluded from the study. Geriatric, paediatric, pregnant and uncooperative patients were also excluded from the study. Those patients who developed muscle weakness before the onset of sensory block were excluded from the study. Also, the patients who showed the signs of weak vocalisation or phonation were also eliminated from study and were intubated to prevent aspiration.

On the day before surgery the patients were attended and examined properly. A detailed medical and surgical history was taken. The patients were also examined for presence of pallor, icterus, cyanosis and clubbing. Blood pressure, pulse rate, respiratory rate and temperature was also noted. Airway was also examined. Body weight and height of each patients were noted. Routine investigation was done. Fasting guidelines was maintained. Patients were explained regarding the procedure and were also taught to interpret the visual analogue scale (VAS) (graded from $0=$ no pain to $10=$ maximum pain). Premedication was given with oral alprazolam $0.25 \mathrm{mg}$ and omeprazole $20 \mathrm{mg}$ night before surgery and alprazolam $0.25 \mathrm{mg} 2$ hours before surgery.

A brachial plexus block tray was kept ready. The two groups receiving the block were unaware of the composition of the drugs used in block.
On arrival of the patient in the operation theatre, BPL Multipara monitors were applied and base line respiratory rate, pulse rate, non-invasive blood pressure, SPO2 and ECG were recorded. Intravenous line was secured with 18G intracath and the patients were given I.V. Fluids according to the requirement.

Patients were sedated with IV midazolam (1-5 mg) and fentanyl (50-250 $\mu \mathrm{g})$, titrated to moderate sedation (arousable on command). All supraclavicular blocks were performed using the approach previously described by Winnie (3). Using a 22-gauge, 50-mm, insulated, blunt needle (Braun Medical, Bethlehem, PA) and a nerve stimulator, a stimulus was sought distal to the shoulder to the tip of little finger. After an appropriate stimulus was localized with a current $\sim 0.5 \mathrm{~mA}, 40 \mathrm{~mL}$ of the study solution as injected in 3$\mathrm{mL}$ increments negative aspiration for air or blood.

Sensory and motor block of the nerves was determined at every 2 minutes after completion of injection. Sensory block was determined by response to pinprick. 0-normal sensation to pin prick, 1-dull response to pin-prick, 2-no response to pin prick. Assessment of motor block by modified Lovett scale ranging from 6 (usual muscular force) to 0 (complete paralysis), was carried every $2 \mathrm{~min}$, till complete motor block after drug injection.

Onset time of sensory block was defined as, the time interval between the end of local anaesthetic injection and loss of sensation to pinprick in all the nerve distributions.

Onset of motor block was defined as the time interval of completion of injection of study drug to first loss of motor power.

Patients were monitored for haemodynamic variables such as heart rate and blood pressure. Heart rate, blood pressure, and $\mathrm{SpO} 2$ were recorded at 10, 30, $60 \mathrm{~min}$ intraoperatively. Each patient was observed for complications like bradycardia, hypotension, dizziness, dryness of mouth, respiratory depression. Patients were discharged from PACU with stable vital signs. Postoperatively intensity of analgesia was evaluated using Visual Analogue Scale (ranging from 0$10)$ and rescue analgesic was given when VAS score $>4$.

\section{Statistical Analysis}

The information collected regarding all the selected cases were recorded in the master chart. Data will be summarized in mean \pm standard deviation or as percentages. Statistical Analysis will be performed using SPSS Ver. 2.0 and comparison of categorical variables between two groups will be done by Chi-Square test or Fisher's exact test, as appropriate. Numerical variables will be normally distributed and will be compared by Student's unpaired ' $t$ ' test. All analysis will be two tailed and $\mathrm{p}<0.05$ will be considered as statistically significant.

\section{RESULTS \\ Group A}

Received $15 \mathrm{ml}$ Inj. Ropivacaine $(0.75 \%)+25 \mathrm{ml}$ of Normal Saline $(40 \mathrm{ml})$.

\section{Group B}

$15 \mathrm{ml}$ Inj. Ropivacaine $(0.75 \%)+23 \mathrm{ml}$ of Normal Saline+ Inj. Magnesium sulfate [2 $\mathrm{ml}(1 \mathrm{gm})](40 \mathrm{ml})$. 


\begin{tabular}{|c|c|c|}
\hline & Group A & Group B \\
\hline Age(Yr) & $37.77 \pm 12.83$ & $36.55 \pm 12.56$ \\
\hline sex(M/F) & $22 / 18$ & $19 / 21$ \\
\hline weight(Kgs) & $57.58 \pm 9.19$ & $56.15 \pm 7.1$ \\
\hline Table A. Comparison of demographic profile \\
between two groups \\
\hline
\end{tabular}

\begin{tabular}{|c|c|c|c|}
\hline & Group A & Group B & P-value \\
\hline $\begin{array}{c}\text { Duration of } \\
\text { surgery(min) }\end{array}$ & $82.38 \pm 19.74$ & $81.25 \pm 21.27$ & 0.807 \\
\hline \multicolumn{3}{|c|}{ Table B. Comparison of duration of surgery } \\
between two groups \\
\hline
\end{tabular}

\begin{tabular}{|c|c|c|c|}
\hline & Group A & Group B & P value \\
\hline $\begin{array}{c}\text { Onset of motor } \\
\text { block(min) }\end{array}$ & $15.85 \pm 3.82$ & $9.20 \pm 2.73$ & $<0.05$ \\
\hline $\begin{array}{c}\text { Onset of sensory } \\
\text { block(min) }\end{array}$ & $20.70 \pm 4.02$ & $11.92 \pm 2.94$ & $<0.05$ \\
\hline $\begin{array}{c}\text { Duration of sensory } \\
\text { block(hrs) }\end{array}$ & $5.25 \pm 1.17$ & $7.85 \pm 1.63$ & $<0.05$ \\
\hline $\begin{array}{c}\text { Table C. Comparison of onset of motor and sensory block } \\
\text { and duration of sensory block between two groups }\end{array}$ \\
\hline
\end{tabular}

\begin{tabular}{|c|c|c|c|}
\hline & Group A & Group B & P-value \\
\hline VAS_6 hr & $4.25 \pm 1.32$ & $1.35 \pm 1.03$ & $<0.05$ \\
\hline VAS_12 hr & $7.40 \pm 1.19$ & $3.33 \pm 0.97$ & $<0.05$ \\
\hline \multicolumn{4}{|c|}{ Table D. Comparison of VAS score at 6th and 12th hour } \\
between two groups \\
\hline
\end{tabular}

\begin{tabular}{|c|c|c|}
\hline & Group A & Group B \\
\hline $\begin{array}{c}\text { Rescue analgesic } \\
\text { requirement }\end{array}$ & $29 / 40$ & $7 / 40$ \\
\hline \multicolumn{3}{|c|}{ Table E. Comparison of requirement of rescue } \\
analgesic between two groups
\end{tabular}

\section{Haemodynamic Variables \\ Heart Rate}

\begin{tabular}{|c|c|c|}
\hline Heart Rate & Group A & Group B \\
\hline PR 0 min & $74.95 \pm 6.41$ & $75.08 \pm 6.99$ \\
\hline PR 10 min & $74.98 \pm 6.38$ & $74.95 \pm 7.12$ \\
\hline PR $30 \mathrm{~min}$ & $75.40 \pm 5.76$ & $74.13 \pm 5.76$ \\
\hline PR $60 \mathrm{~min}$ & $74.98 \pm 6.07$ & $74.60 \pm 6.48$ \\
\hline Table F. Mean, Standard deviation and P-value chart of \\
recorded Heart Rate \\
\hline
\end{tabular}

( $\mathrm{P}$ value for all the above observations $>0.05$ )

Mean Blood Pressure

\begin{tabular}{|c|c|c|c|}
\hline Mean \& SD & Group A & Group B & P value \\
\hline MBP 0 min & $83.53 \pm 9.251$ & $84.73 \pm 10.08$ & 0.581 \\
\hline MBP 10 min & $82.98 \pm 7.78$ & $84.83 \pm 9.87$ & 0.355 \\
\hline MBP 30 min & $83.25 \pm 8.42$ & $84.78 \pm 9.899$ & 0.460 \\
\hline MBP 60 min & $83.41 \pm 9.22$ & $85.41 \pm 9.87$ & 0.352 \\
\hline
\end{tabular}

\section{Table B. Mean, Standard deviation and P-value chart of} recorded mean blood pressure

\section{Oxygen Saturation}

\begin{tabular}{|c|c|c|c|}
\hline Mean \& SD & Group A & Group B & P value \\
\hline $\mathrm{SpO}_{2} 0 \mathrm{~min}$ & $83.53 \pm 9.251$ & $84.73 \pm 10.08$ & 0.581 \\
\hline $\mathrm{SpO}_{2} 10 \mathrm{~min}$ & $82.98 \pm 7.78$ & $84.83 \pm 9.87$ & 0.355 \\
\hline $\mathrm{SpO}_{2} 30 \mathrm{~min}$ & $83.25 \pm 8.42$ & $84.78 \pm 9.899$ & 0.460 \\
\hline $\mathrm{SpO}_{2} 60 \mathrm{~min}$ & $83.41 \pm 9.22$ & $85.41 \pm 9.87$ & 0.352 \\
\hline \multicolumn{4}{|c|}{ Table B. Mean, Standard deviation and P-value chart of } \\
recorded mean blood pressure \\
\hline
\end{tabular}

\section{DISCUSSION}

Surgical pain is a universal phenomenon, affecting all patients in the perioperative period, causing several deleterious effects on patient's body and mind. It is the moral responsibility of the perioperative physician like anaesthesiologist and surgeon to provide adequate postoperative analgesia not only to suppress the adverse physiological responses to pain, but also to improve the quality of patient care following surgery.

Supraclavicular block is a popular and widely employed regional nerve block technique for perioperative anaesthesia and analgesia for surgery of upper extremity. Local anaesthetics alone for supraclavicular brachial plexus block provide good operative condition but have shorter duration of postoperative analgesia. So various drugs as adjuvants were used with local anaesthetic in brachial plexus block to achieve quick, dense and prolonged block.

A variety of receptors mediate anti-nociception on peripheral sensory axons. The peripheral administration of appropriate drugs (adjuncts) may have analgesic benefit and reduce systemic adverse effect. In an attempt to improve perioperative analgesia, a variety of adjuncts like opioids, clonidine, neostigmine and tramadol have been administered concomitantly via local anaesthetic into the brachial plexus sheath. The aim of this study is to evaluate and compare whether additional anaesthetic and analgesic effects could be achieved from administration of magnesium sulphate into brachial plexus sheath.

Although the mechanism of analgesia produced by magnesium is not fully understood, many authors have reported that magnesium is associated with reduced analgesic requirement and less discomfort in the postoperative period. The primary hypothesis for analgesic property is the surface charge theory. Akutagawa et al. ${ }^{8}$ Showed that modulation of the external magnesium concentration bathing a nerve bundle resulted in enhancement of the nerve blockade by the local anaesthetic. Mert et al. ${ }^{9}$ Reported that high concentration of divalent ions ( $\mathrm{Mg}$ and $\mathrm{Ca}$ ) attracted by the negative charges of the outer membrane surface affected Na channel gating and could cause hyperpolarization. If the nerve fibre is hyperpolarized, it is more difficult to achieve the threshold level, and it results in the nerve conduction block. Another possible mechanism for the analgesic action of magnesium is the voltage-dependent antagonism of NMDA receptors, leading to the prevention of central sensitization from the peripheral nociceptive stimulation and a decrease in the acute pain after tissue injury. The analgesic benefit observed in our study is consistent with that reported by Gunduz e tal. ${ }^{10}$

Who investigated the effect of perineural or systemic magnesium on the duration of axillary plexus block.

In our study we have compared the effect of magnesium on motor and sensory block when added as adjuvant with ropivacaine in relation to ropivacaine alone in Supraclavicular Brachial plexus block.

Eighty ASA I-II patients were divided into two groups of forty patients each. Group A received only ropivacaine with normal saline while Group B received ropivacaine, normal saline and magnesium sulphate. In Group B onset of motor block was $9.20 \pm 2.73$ minutes which was faster in comparison to Group A where it was $15.85 \pm 3.82$ minutes. In respect to the onset of sensory block also it was found to be faster in case of 
Group B i.e. $11.92 \pm 2.94$ in comparison to Group A where it was $20.70 \pm 4.02$ minutes.

The total duration of perioperative and postoperative analgesia was found to longer to be in Group B i.e $7.85 \pm 1.62$ hours.

The VAS score in 6 th postoperative hour was $<4$ in Group B $(1.35 \pm 1.03)$ in comparison of Group A $(4.25 \pm 1.32)$. The VAS score in 12 th hour was also less in Group B $3.33 \pm 0.97$ while in Group A it was $7.40 \pm 1.19$. The requirement of rescue analgesic was seen in 29 patients in Group A in comparison to only 7 patients in Group B.

The perioperative haemodynamic parameters at initial, 10 min, 30 min and 60 min interval were comparable in both the groups.

\section{CONCLUSION}

Thus, in conclusion, addition of magnesium sulphate to ropivacaine in supraclavicular brachial plexus block hastens the onset of motor and sensory block and prolongs the duration of sensory block in the postoperative period.

\section{REFERENCES}

[1] Mckenzie PJ, Loach AB. Local anaesthesia for orthopaedic surgery. Br J Anaesth 1986;58(7):779-89.

[2] Khanduri KC. Regional anesthesia techniques for orthopaedic surgery. Med J Armed Forces India 2008;64(2):108-10.
[3] Fredrickson MJ, Krishnan S, Chen CY. Postoperative analgesia for shoulder surgery: a critical appraisal and review of current techniques. Anaesthesia 2010;65(6):608-24.

[4] Albright GA. Cardiac arrest following regional anaesthesia with etidocaine or bupivacaine. Anesthesiology 1979;51(4):285-7.

[5] Cummings KC, Napierkowski DE, Parra-Sanchez I, et al. Effect of dexamethasone on the duration of interscalene nerve blocks with ropivacaine or bupivacaine. $\mathrm{Br} \mathrm{J}$ Anaesth 2011;107(3):446-53.

[6] Soave PM, Conti G, Costa R, et al. Magnesium and anaesthesia. Curr Drug Targets 2009;10(8):734-43.

[7] Bilir A, Gulec S, Erkan A, et al. Epidural magnesium reduces postoperative analgesic requirement. $\mathrm{Br} \mathrm{J}$ Anaesth 2007;98(4):519-23.

[8] Akutagawa T, Kitahata LM, Saito H, et al. Magnesium enhances local anesthetic nerve block of frog sciatic nerve. Anesth Analg 1984;63(2):111-6.

[9] Mert T, Gunes Y, Guven M, et al. Effects of calcium and magnesium on peripheral nerve conduction. Pol J Pharmacol 2003;55(1):25-30.

[10] Gunduz A, Bilir A, Gulec S. Magnesium added to prilocaine prolongs the duration of axillary plexus block. Reg Anesth Pain Med 2006;31(3):233-6. 